\title{
Transverse testicular ectopia associated with incarcerated inguinal hernia: a case report Duygu Tatli ${ }^{1}$ and Kemal Varim Numanoglu*2
}

\author{
Address: ${ }^{1} \mathrm{MD}$, Assist. Dr. Department of Pediatric Surgery, School of Medicine, Zonguldak Karaelmas University, Kozlu, Zonguldak, Turkey and \\ ${ }^{2} \mathrm{MD}$, Assist. Prof. Department of Pediatric Surgery, School of Medicine, Zonguldak Karaelmas University, Kozlu, Zonguldak, Turkey \\ Email: Duygu Tatli - dddtatli@mynet.com; Kemal Varim Numanoglu* - varimk@yahoo.com \\ * Corresponding author
}

Published: 30 September 2008

Cases Journal 2008, I:200 doi:10.1 186/1757-1626-I-200

This article is available from: http://www.casesjournal.com/content/l/l/200

(c) 2008 Tatli and Numanoglu; licensee BioMed Central Ltd.

This is an Open Access article distributed under the terms of the Creative Commons Attribution License (http://creativecommons.org/licenses/by/2.0), which permits unrestricted use, distribution, and reproduction in any medium, provided the original work is properly cited.
Received: 28 August 2008

Accepted: 30 September 2008

\begin{abstract}
Transverse testicular ectopia is rarely associated with incarcerated inguinal hernia. A I4-month-old male complaint of irreducible inguinal hernia due to transverse testicular ectopia is reported. The clinical and operative findings and treatment options are discussed. It is thought that surgeons who frequently repair inguinal hernias should be aware of the appropriate surgical management options available to them when this condition is unexpectedly identified during inguinal exploration.
\end{abstract}

\section{Background}

Transverse testicular ectopia (TTE) is a rare scrotal anomaly occurring consequent to the migration of both gonads to the same hemiscrotum. The ectopic testis may be located on the inner inguinal ring, in the inguinal canal, or in the contralateral hemiscrotum.[1,2] Although seen characteristically as an ipsilateral inguinal hernia and contralateral undescended testis, the diagnosis can be established only during surgical exploration.

Hereby, a case has been presented, which had been prediagnosed as having an incarcerated inguinal hernia, and taken into operation in which transverse testicular ectopia was detected.

\section{Case report}

A 14-month-old male was admitted with the complaints of vomiting and painful right inguinal swelling. This swelling had been present for about one month, but in the last 8 hours, the swelling had become pronounced and tender.
On physical examination, there was an incarcerated inguinal hernia in the right groin. The left testis could not be palpated in the scrotum or the inguinal canal. The patient was taken to the operation room as soon as appropriate preoperative preparations had been completed. At the time of operation, right inguinal region explored. Hernia sac and cord structures traversing the internal inguinal ring were identified. Unexpectedly, a second testis with a well-grown vas deferens and testicular vessels was found incarcerated at the level of the internal ring (Fig. 1). There were two vas deferenses and vascular structures accompanying each gonad. Following medial elongation of the incision, the existence of Müllerian remnants was eliminated. Following hernia repair, the ectopic gonad was fixed to the opposite hemiscrotum through a transseptal route.

No complications occurred in the postoperative period. Abdominal ultrasound and the voiding cystourethrogram revealed normal findings. 




Figure I

Operative wiew during right inguinal exploration. All structures delivered through right groin incision as seen. Asterisk (*) denotes incarcerated gonad.

\section{Discussion}

Although rare, transverse testicular ectopia, occurring secondary to the migration of both testes to the same hemiscrotum, is a well-known congenital anomaly. This finding was first reported by Lenhossek in 1886, as an autopsy finding.[3] In the following years, over 100 cases have been reported.

The embryologic etiology of TTE is controversial. Several theories such as adhesion and fusion of developing Wolffian canals, aberrant gubernaculum, testicular adhesions, defective formation of the internal inguinal ring and traction on a testis by persistent müllerian structures have been suggested. Persistent müllerian duct structures (PMDS) may result from the failure of synthesis or releases of müllerian duct inhibitory factor (MIF), the failure of end organs to respond to MIF, or defect in the timing of the release of MIF. It seems possible that the mechanical effect of the persistent müllerian duct structures prevents the testicular descent or leads to both testicles descending toward the same hemiscrotum, producing TTE.[4] The association with cryptorchidism is accompanied by an increase in malignancy potential of crossed ectopic testes with malignancy rates similar to undescended testes.

Transverse testicular ectopias are classified into three types according to the existence of various additional anomalies:[1]

\section{Observed only with inguinal hernia (40-50\%).}

2. Observed with persistent or rudimentary Mullerian duct structures (30\%).
3. Observed with additional anomalies other than Mullerian remnants (inguinal hernia, hypospadias, pseudohermaphroditism, and scrotal anomalies) (20\%).

TTE patients are generally admitted due to inguinal hernia on the migrated side of the ectopic testis or an undescended testis on the opposite side. However, there have only been four cases admitted with incarceration as in the present case. [5-8]

In many cases, the diagnosis may be established during the operation. However, there are also articles reporting that preoperative diagnosis may be established by ultrasound, computerized tomography, magnetic resonance imaging or magnetic resonance venography.[9]

The treatment of transverse testicular ectopia is focused on the detection of associated congenital abnormalities and placement of ectopic testicles into anatomical positions. This preserves fertility and allows monitoring for the development of malignancy. If two gonads come into view during exploration of one inguinal side, complete abdominal exploration must be performed. Intraoperative intraabdominal evaluation via mini laparotomy or transinguinal diagnostic laparoscopy allows for detection of müllerian structures and genitourinary congenital abnormalities. A biopsy should be taken from tissue remnants between cord structures or abdomen. There is no report of malignancy arising from the retained müllerian structures, and the absence of MIF does not appear to increase the relative risk of testicular malignancy. Therefore, routine hysterectomy is not recommended in patients who have obvious uterus and fallopian tubes. Extensive dissection of vas deferenses and excision of persistent müllerian duct structures should be avoided to prevent the injury.[4]

Transseptal orchiopexy or extra-peritoneal transposition of the testis is the treatment of choice. Long-term followup should be performed as the possibility of infertility and malignant transformation is rather high.[10]

Transverse testicular ectopia, characteristically accompanied by ipsilateral inguinal hernia, and a contralateral undescended testis, is a rare anomaly. The present case is the fifth case in the literature admitted with findings of incarceration and described after emergent surgery. Surgeons who frequently repair inguinal hernias should be aware of the appropriate surgical management options available to them when this condition is unexpectedly identified during inguinal exploration. It is thought that it will be beneficial to keep this rare clinical entity in mind, in cases of incarcerated inguinal hernia with contralateral undescended testis. 


\section{Consent}

Written informed consent was obtained from the patient's parents for publication of this case report and accompanying images. A copy of the written consent is available for review by the Editor-in-Chief of this journal.

\section{Competing interests}

The authors declare that they have no competing interests.

\section{Authors' contributions}

DT and KVN were involved in the treatment of the patient and wrote and finalized the manuscript. All authors read and approved the final manuscript.

\section{References}

I. Gauderer MW, Grisoni ER, Stellato TA, Ponsky JL, Izant RJ Jr: Transverse testicular ectopia. J Pediatr Surg 1982, I7(1):43-47.

2. Kale N, Başaklar AC: Transvers testiküler ektopi. Pediatrik Cerrahi Dergisi 1989, 3:165-166.

3. Von Lenhossek M: Ectopia testis transversa. Anta Anz 1886, I:376.

4. Karnak I, Tanyel FC, Akçören Z, Hiçsönmez A: Transverse testicular ectopia with persistent müllerian duct syndrome. J Pediatr Surg 1997, 32(9): I362-1364.

5. Dickinson AJ, Hewett P: Transverse testicular ectopia presenting as strangulated inguinal hernia. $\mathrm{Br} J$ Urol 1990, 66(2):217.

6. Vaos G, Zavras N: Irreducible inguinal hernia due to crossed testicular ectopia in an infant. Hernia 2004, 8(4):397-398.

7. Kuwayama DP, Peterson JE: Transverse testicular ectopia in a fertile elderly male presenting with incarcerated inguinoscrotal hernia. Hernia 2008, I2(3):3|3-315.

8. Shamim M: Persistent Mullerian duct syndrome with transverse testicular ectopia presenting in an irreducible recurrent inguinal hernia. J Pak Med Assoc 2007, 57(8):42I-423.

9. Lam WW, Le SDV, Chan KL, Chan FL, Tam PKH: Transverse testicular ectopia detected by $M R$ imaging and $M R$ venography. Pediatr Radiol 2002, 32:126-129.

10. Fairfax CA, Skoog SJ: The laparoscopic diagnosis of transverse testicular ectopia. J Urol 1995, I53(2):477-478.
Publish with Bio Med Central and every scientist can read your work free of charge

"BioMed Central will be the most significant development for disseminating the results of biomedical research in our lifetime. "

Sir Paul Nurse, Cancer Research UK

Your research papers will be:

- available free of charge to the entire biomedical community

- peer reviewed and published immediately upon acceptance

- cited in PubMed and archived on PubMed Central

- yours - you keep the copyright

Submit your manuscript here:

http://www.biomedcentral.com/info/publishing_adv.asp
BioMedcentral 